\title{
Environmental safety aspects and basic development trends in the Russian pharmaceutical market
}

\author{
Lyudmila Kopteva ${ }^{1 *}$, Lyudmila Shabalina ${ }^{2}$, Roman Bolshakov ${ }^{3}$, and Anton Smirnov ${ }^{3}$ \\ ${ }^{1}$ Saint-Petrsburg State University of Aerospase Instrumentation, Bolshaya Morskaia str., 67, Saint- \\ Petersburg, 190000, Russia \\ ${ }^{2}$ Donetsk National Technical University, Artema str., 58, Donetsk, 83000, Ukraine \\ ${ }^{3}$ State University of the Sea and River Fleet named after Admiral S.O. Makarov, ul. Dvinskaya, 5/7, \\ St. Petersburg, 198035, Russia
}

\begin{abstract}
The purpose of the paper is to determine the level of environmental safety and the main trends in the development of the pharmaceutical market of the Russian Federation. In the research process, methods of theoretical generalization and comparison, synthesis and statistical analysis were used. The trends of environmental safety of the Russian pharmaceutical market are considered. The problems and prospects for the development of the Russian pharmaceutical market as well as the market for medicines are identified. Promising segments of the pharmaceutical market of the Russian Federation have been identified on the basis of assessing the conformity of manufactured and imported goods to the List of vital and essential drugs, which will allow Russian pharmaceutical companies to improve their position in the national market by increasing the production and sales of their own medicines. The obtained results are aimed at developing the pharmaceutical market of Russia in an unstable economic and political situation. Based on this study, it is possible to develop tools aimed at reducing the import dependence of the Russian Federation.
\end{abstract}

\section{Introduction}

One of the main ways of ensuring national security in the medium term is environmental safety and a guaranteed supply of high-quality and affordable medicines to the population.

Nowadays, the current demographic situation in Russia is caused by aging and a high mortality rate, as well as an increase in the prevalence of chronic diseases. In 2017, compared with 2016, the mortality rate from diseases of the respiratory system increased by $9 \%$, from infectious and oncological diseases - by 6 and 5\%, respectively [1]. At the same time, the share of medicines produced in the Russian Federation, according to the results of 2017, amounted to $30 \%$ in monetary terms and $62 \%$ in real terms [2]. Due to the imposition of sanctions by the European Union, the United States and a number of countries

*Corresponding author: doptaganka@yandex.ru 
supporting their position, the existing import dependence of the Russian Federation can lead to a lack of medicines for the population, a decrease in life expectancy and an increase in mortality. Due to these circumstances, it is necessary to study the trends of the Russian pharmaceutical market in order to develop a development strategy for the production of domestic medicines (drugs).

Assessment of the availability and accessibility of drugs at the international level is carried out by the World Health Organization (WHO), the Pharmaceutical Security Institute (PSI), the European Federation of the Pharmaceutical Industries and Associations (EFPIA). A significant contribution to the study of the problem of drug safety in the Russian Federation was made by V.A. Balashov, I.A. Sadchikov, S.M. Panchuk, N.I. Yabluchansky. V.L. Bagirova, N.N. Kareva, L.V. Moshkova are considering issues of increasing the effectiveness of the choice of drugs to fully meet the needs of the healthcare system of the Russian Federation.

In 2017, 148.8 million people lived in the Russian Federation, of which the number of people over the age of 60 y.o. was $21.2 \%$, which is $8.2 \%$ more than the global average. Compared to 2008, a $3.8 \%$ increase in the population of people over 60 years old occurred, which led to a decrease in the number of people of working age by $0.4 \%$. These circumstances indicate an aging of population and an increase in demand for drugs (Fig. 1).

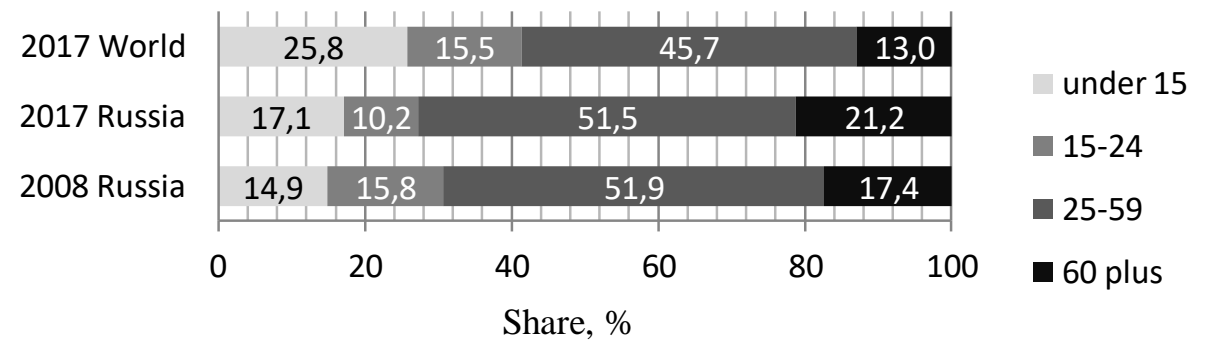

Fig. 1. Age composition of the world population and the Russian Federation (prepared according to the source [3]).

The number of births in Russia in 2017 is $10.5 \%$ less compared to 2016 and $1.4 \%$ compared to 2008 [1] - this indicates depopulation in the future. In 2017, there was a drop in the natural population growth of the Russian Federation compared to 2008 and 2016 by 1.6 and $1.1 \%$, respectively. According to the WHO forecast, in comparison with 2017, in 2020, the population of the Russian Federation will decrease by $4 \%$, and in 2030 - by $5.5 \%$. While the global average population growth in 2020 and 2030 will increase by 2.9 and $4.5 \%$, respectively, compared with 2017 [3]. Since 2016, there has been a significant decrease in the population of the Russian Federation, which indicates an increase in the aging trend of the population in the future.

In $2017,43 \%$ of the population of the Russian Federation died from diseases of the cardiovascular system (the global average is $26.6 \%$ ). Mortality from cancer was $18 \%$, infectious and parasitic diseases - $9 \%$. The cause of death of $12 \%$ of the population was a disease of the digestive tract and respiratory organs, then the global average mortality rate from respiratory diseases is $14.3 \%$ [4] (Fig. 2). 


\begin{tabular}{|c|c|c|c|c|c|c|c|c|c|c|}
\hline \multirow{3}{*}{ 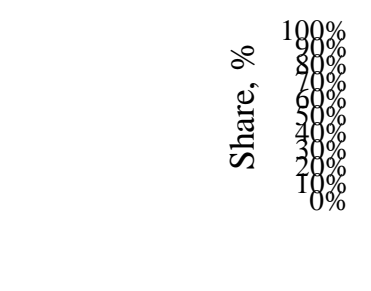 } & 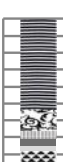 & & & & & $=$ & $=$ & $=$ & - & \\
\hline & 20 & 20 & 20 & 20 & 20 & 20 & 20 & 20 & 20 & $\overline{20}$ \\
\hline & 08 & 09 & 10 & 11 & 12 & 13 & 14 & 15 & 16 & 17 \\
\hline Cardiovascular disease & 53 & 56 & 57 & 56 & 54 & 53 & 49 & 48 & 47 & 43 \\
\hline Oncology & 13 & 12 & 14 & 15 & 15 & 16 & 16 & 15 & 15 & 18 \\
\hline $\begin{array}{l}\text { Infections and parasitic } \\
\text { diseases }\end{array}$ & 4 & 2 & 1 & 2 & 3 & 3 & 7 & 9 & 10 & 9 \\
\hline Respiratory diseases & 5 & 4 & 4 & 4 & 4 & 4 & 4 & 4 & 4 & 6 \\
\hline $\begin{array}{l}\text { Digestive system } \\
\text { diseases }\end{array}$ & 3 & 4 & 5 & 5 & 5 & 5 & 4 & 5 & 6 & 6 \\
\hline Other diseases & 8 & 8 & 8 & 8 & 9 & 10 & 12 & 10 & 11 & 12 \\
\hline External causes & 14 & 14 & 11 & 10 & 10 & 9 & 8 & 9 & 7 & 6 \\
\hline
\end{tabular}

Fig. 2. Dynamics of the main causes of mortality (prepared according to the source [5])

The main causes of population mortality by gender indicate that more men than women die, $47 \%$ from respiratory diseases, $46.7 \%$ from infectious and parasitic diseases, $12.9 \%$ from oncological diseases, which is explained by severe and dangerous working conditions at enterprises, the presence of bad habits, as well as neglect of the timely treatment of diseases of this type. In 2017, the number of breast cancer diseases in women increased by $32.5 \%$ compared to 2008 [1]. Over the past 10 years, the incidence of lung and stomach cancer has increased by 20 and $11 \%$, respectively, in both women and men, which indicates the need to study the factors affecting the increase in the incidence, development and introduction of new oncological drugs on the market [6]. For the period from 2011 to 2017, there was an increase in HIV detection cases by $20.1 \%$. This is due to a decrease in responsibility for prevention and an increase in the number of unprotected sexual acts, which is a global trend [7]. The incidence rate of tuberculosis in 2017 increased by $70 \%$ compared to 2008. In this regard, it is necessary to study the market of drugs for the treatment of respiratory diseases in order to identify groups of drugs and analyze their production as generic in the Russian Federation [8].

At the end of 2017, the capacity of the pharmaceutical market of the Russian Federation amounted to 1629 billion rubles, which is $28 \%$ higher than in 2008. Financing from budgetary funds amounted to $25.9 \%$ of the market. The volume of the commercial segment of the pharmaceutical market in 2017 is $74.1 \%$. For the period from 2008 to 2017, there was an increase in this sector by 3.5 times, which indicates an increase in the commercialization of the market. The sector of biologically active additives (BAA) in the world is about $36 \%$ of the total market, in Russia this segment amounted to $16.3 \%$ in 2017 , which shows an increase of 2.5 times compared to 2008. This confirms the negative trend of an increase in the production of dietary supplements and their use by the population as a drug for the treatment of diseases, which leads to an increase in mortality due to the lack of timely treatment with the necessary drugs (Fig. 3). 


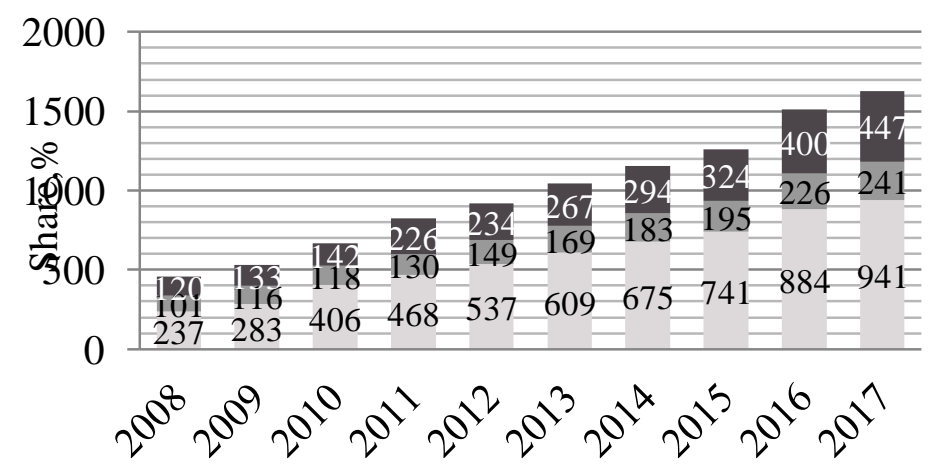

\section{- Public sector of drugs}

Commercial sector of dietary supplements

Fig. 3. Market capacity in final consumer prices, billion rubles (prepared according to the source [2])

One of the evaluation criteria of the population's need for pharmaceutical products is the structure of retail pharmacy sales (RPS) [9]. Analysis of the product range of drugs was carried out on the basis of a list of vital and essential drugs grouped according to the international system of classification of drugs (Anatomical Therapeutic Chemical - ATC). The most popular in 2017 are drugs for the treatment of diseases of the digestive tract and metabolism, which make up $16.4 \%$ in value, antimicrobial - 12.5 , oncological -10.7 , for the treatment of diseases of the nervous and cardiovascular system - 10.2 and $10.1 \%$, respectively (Fig. 4) [2]. For the period from 2008 to 2017, there was an increase in demand for oncological and antimicrobial drugs by 6 and $4.8 \%$, respectively, due to the presence of bad habits, lack of physical activity, environmental pollution and exposure to radiation. Also, the demand for circulatory system drugs increased by $4.5 \%$ due to the population aging. 

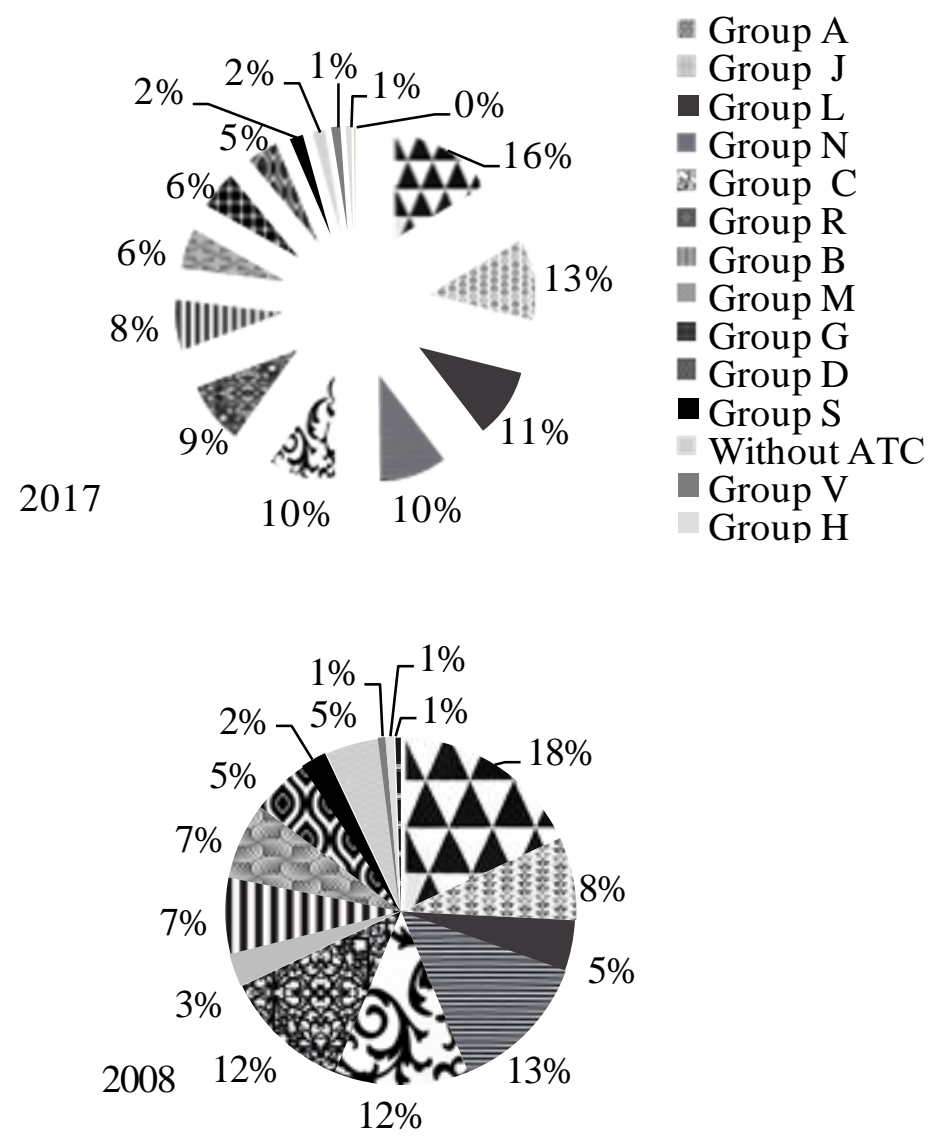

Fig. 4. The share of drugs by ATC groups in cost volume (prepared according to the source [1])

In 2008-2017, the share of imported drugs decreased by $4 \%$ in physical terms and by $5.8 \%$ in monetary terms, which is associated with the state policy of import substitution in the Russian Federation [2]. The share of Russian-made drugs in 2017 was 30\% in monetary terms and $62 \%$ in real terms (Fig. 5). Whereas according to the WHO drug supply criterion, national production should be at least $70 \%$. In Russia, this criterion does not meet the standards, despite the increase in the number of products of own production in the pharmaceutical market. Due to these circumstances, the question arises of the need to increase the national market sector and the orientation of Russian companies on the production of necessary drugs. 


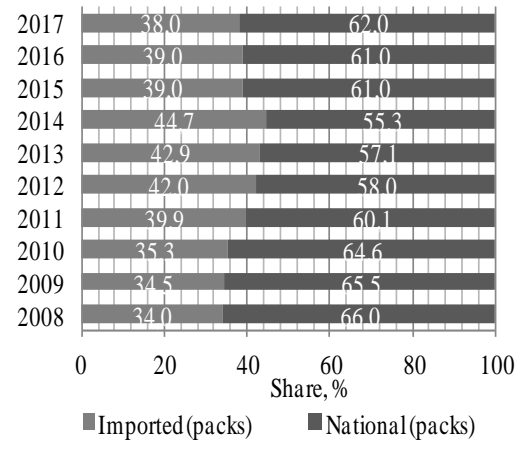

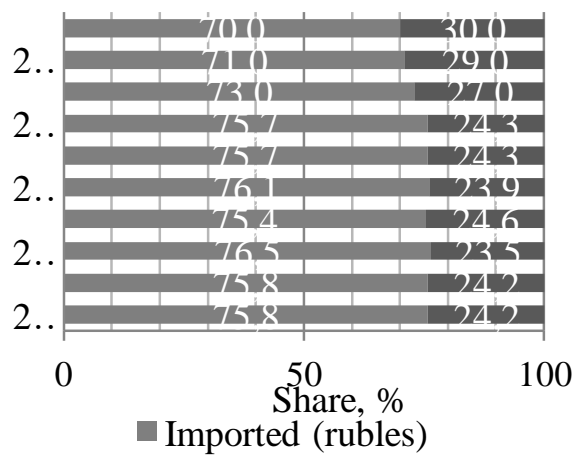

Fig. 5. Market structure in the context of national and imported drugs (prepared according to the source [2])

An analysis of the share of Russian drugs in the list of vital and essential drugs in 2017 showed that $84 \%$ of the nomenclature of drugs are national, while in 2018 , it is planned to bring this indicator to $90 \%$ (Fig. 6) [5].

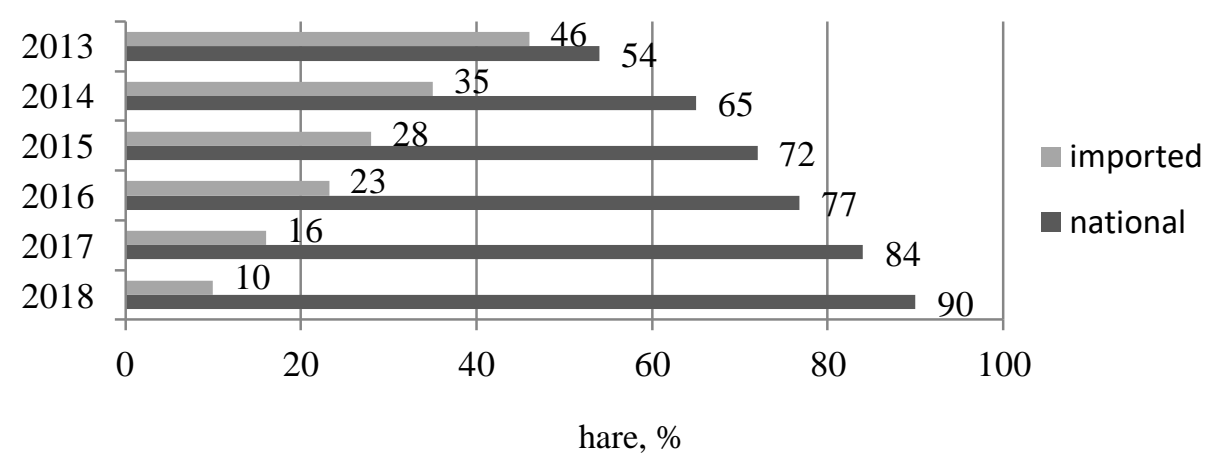

Fig. 6. The share of domestic drugs in the list of vital and essential drugs (prepared according to the source [5])

Despite the increase in the indicator, in the pharmacy chains of many regions, there are less than a third of the drugs listed in the list of vital and essential drugs, and there is also a tendency to increase retail prices for drugs from the list. The most noticeable price increases are observed in the Khabarovsk Territory (1.7\%), the Republic of Mordovia (1.5\%), the Leningrad Region (1.3\%), the Penza Region $(0.8 \%)$, and in St. Petersburg $(1.2 \%)$, which testifies to the different supply of medicines to the republics and the need for the additional state control of the price policy of vital drugs [5]. A quantitative assessment of drug safety includes determining the degree to which the country's population is provided with essential drugs (see table). 
Table 1. List of vital and essential drugs, $\%^{1}$

\begin{tabular}{|c|c|c|c|c|c|c|}
\hline \multirow{2}{*}{$\begin{array}{c}\text { ATC } \\
\text { code }\end{array}$} & \multirow{2}{*}{$\begin{array}{c}\text { Anatomical Therapeutic Chemical } \\
\text { classification (ATC) }\end{array}$} & \multicolumn{2}{|c|}{$\begin{array}{c}\text { Share in } \\
\text { the list }\end{array}$} & $\begin{array}{c}\text { Share in } \\
\text { RPS }\end{array}$ & $\begin{array}{c}\text { Share in } \\
\text { the list }\end{array}$ & $\begin{array}{c}\text { Share in } \\
\text { RPS }\end{array}$ \\
\cline { 3 - 6 } & \multicolumn{2}{|c|}{2013} & \multicolumn{2}{|c|}{2017} \\
\hline A & Digestive tract and metabolism & 9 & 19.3 & 10 & 16 \\
\hline B & Circulatory system & 8 & 3.4 & 8 & 8 \\
\hline C & Cardiovascular system & 8 & 12.3 & 7 & 10 \\
\hline D & Dermatological preparations & 2 & 6.1 & 1 & 5 \\
\hline G & Genitourinary system and sex hormones & 4 & 7.4 & 3 & 6 \\
\hline H & Hormonal drugs & 3 & 0.6 & 4 & 1 \\
\hline J & Antimicrobials & 20 & 7.7 & 18 & 13 \\
\hline L & Oncological drugs & 15 & 4.2 & 19 & 11 \\
\hline M & Musculoskeletal system & 3 & 7.7 & 3 & 6 \\
\hline N & Nervous system & 15 & 11.8 & 13 & 10 \\
\hline P & Antiparasitic drugs & 1 & 0.3 & 1 & 1 \\
\hline R & Respiratory system & 4 & 12.7 & 5 & 9 \\
\hline S & Sensory organs & 2 & 2.6 & 2 & 2 \\
\hline V & Other drugs & 5 & 3.8 & 6 & 2 \\
\hline
\end{tabular}

${ }^{1}$ Prepared according to the source [10].

As a result of comparing the structure of the list of vital and essential drugs and RPS of the drug segment by ATC classification groups, the lack of digestive tract and metabolic drugs was found to be $6 \%$, dermatological - 4\%, respiratory and cardiovascular drugs - 4 and $3 \%$, respectively, genitourinary and musculoskeletal system - by $3 \%$. This indicates the need for Russian companies to focus on these drugs. Based on the main causes of mortality, the demand for oncological drugs is growing, but their share in retail pharmacy sales is $4.2 \%$, which is caused by the organization of preferential drug supply for oncological drugs by the state. To change the structure of vital and essential drugs, it is advisable to analyze the main Russian manufacturers of medicines (Fig. 7).

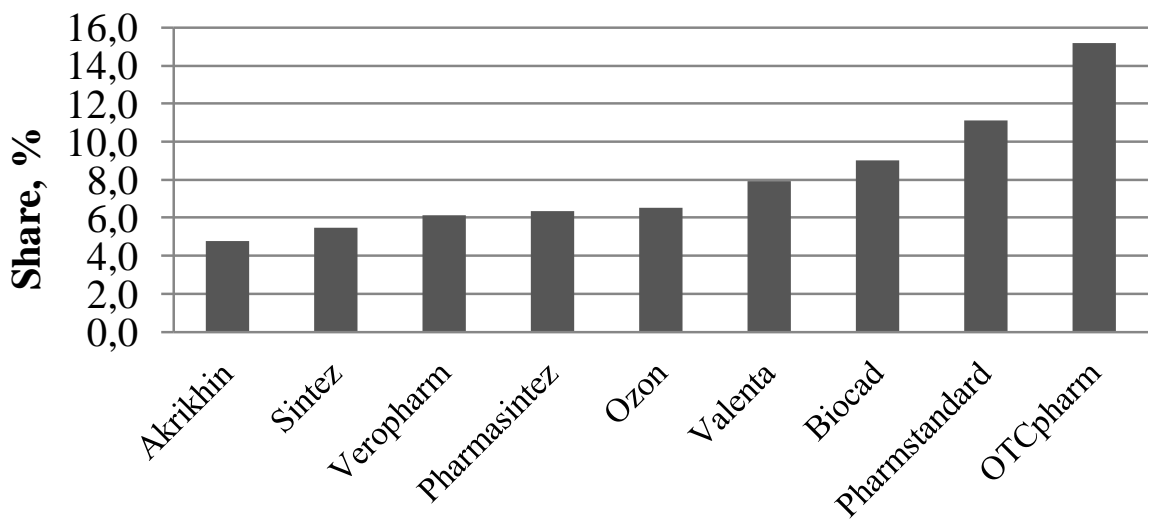

Fig. 7. Rating of Russian drug manufacturers by sales volume, billion rubles.

Ozon and Akrikhin are the main Russian manufacturers of drugs for the treatment of diseases of the cardiovascular system and blood circulation, whose market share is 26 and $23 \%$, respectively. Digestive tract drugs in the largest amount are produced by the Sintez company $-31 \%$. The main companies whose activities are aimed at the production of drugs for oncological diseases are Biocad - 35\% and Sintez - 34\%. Drugs for the treatment of diseases of the musculoskeletal system are produced by the smallest number of companies, the main of which is Akrikhin (94\%). The largest share of drugs for the treatment of 
diseases of the respiratory system is Pharmasintez (55\%). In most companies, production is focused on drugs that are not included in the list of vital and essential drugs. Thus, vitamins and dietary supplements account for $47 \%$ of the total production of OTCpharm, the market leader in terms of sales. The share of dietary supplements in the Pharmstandard production volume is $15 \%$, and Ozon - $6 \%$ (Fig. 8).

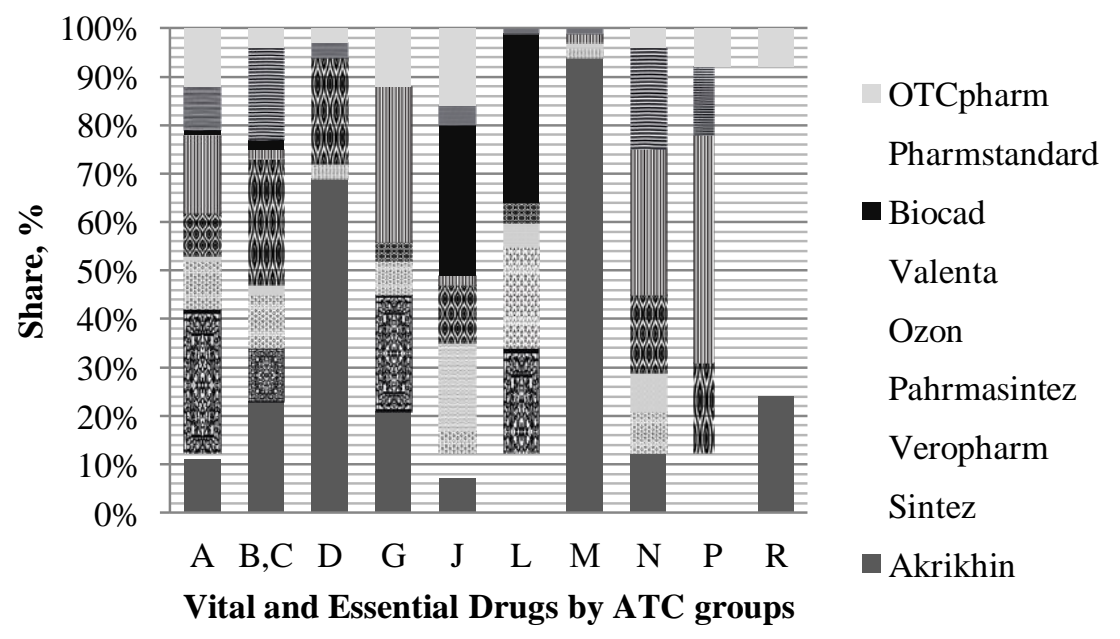

Fig. 8. Production of vital and essential drugs by Russian companies by ATC groups.

The largest part of the Russian pharmaceutical market is made up of drugs for the treatment of diseases of the digestive tract (16.4\%), the share of antimicrobials is $12.5 \%$, oncological $-10.7 \%$, for the treatment of diseases of the nervous system $-10.2 \%$, of the cardiovascular system $-10.1 \%$, respiratory system $-9.4 \%$ (Fig. 9).
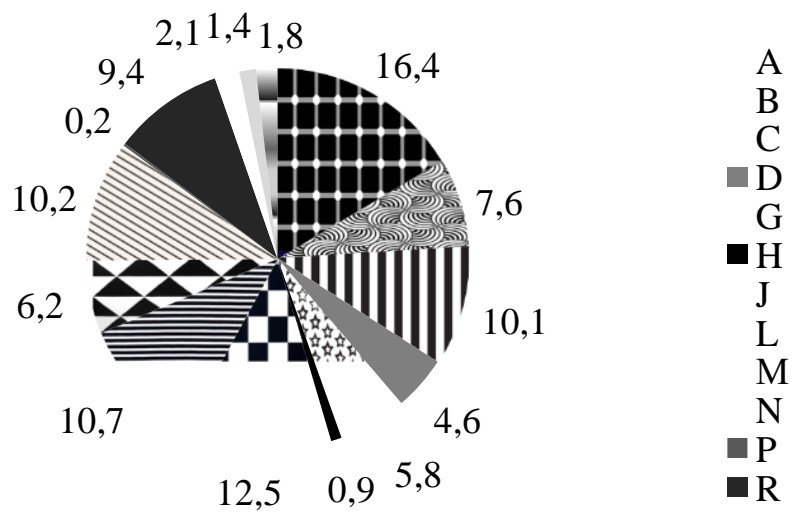

Fig. 9. The share of essential drugs of domestic manufacturers in the Russian market (prepared according to the source [2]).

In the near future, the Russian pharmaceutical market will be focused on the needs of an aging population, as a result of which innovative products for the treatment of the cardiovascular, musculoskeletal systems and chronic diseases will be in demand [11]. In this regard, it is necessary to carry out R\&D in these areas using bio- and nanotechnologies, 
in particular, develop and release new drugs, improve the policy of stimulating the Russian production of drugs by creating state programs, introducing benefits and supporting national manufacturers.

To prevent an environmental chemical pharmaceutical catastrophe of the 21 st century, it is necessary to have a new direction in environmental science - the ecology of medicines. More precisely: environmental toxicology of medicines (drugs) - the study of the life cycle of drugs in the environment and the effects of drug residues on a variety of living organisms.

As a temporary way to prevent intoxication of the body from drugs in drinking water, it is possible suggest the following: drink bottled mineral water extracted from the deep layers of the earth.

It should be noted that modern chemical pharmaceuticals are very complex and pure substances. Therefore, a very large number of various additional chemicals are used in their production. All this leads to significant waste. After consumption, drugs [12] enter the environment in various ways and create environmental pharmaceutical pollution.

Using conventional water treatment processes such as chlorination, approximately $50 \%$ of pharmaceuticals can be removed, while more advanced treatment processes such as ozonation, advanced oxidation, activated carbon filtering, nanofiltration and reverse osmosis can achieve higher removal rates. So, for example, using reverse osmosis, you can remove more than $99 \%$ of large molecules of pharmaceuticals.

Traditional methods for the disposal of drugs are burning, high-temperature treatment with or without air oxygen, or their disposal at solid domestic waste landfills, resulting in atmospheric pollution with highly toxic compounds: carbon oxides, sulfur, phosphorus, arsenic, selenium, phosgene, dicyan, dioxins and other compounds. Thermal disposal is a highly expensive disposal process.

\section{Conclusions}

The influence of the pharmaceutical market of the Russian Federation on environmental safety is analyzed. It is revealed that for the period from 2008 to 2017, the capacity of the Russian pharmaceutical market increased by $28 \%$, while the availability of Russian drugs is $30 \%$ of the market, which does not meet WHO standards. Based on the analysis of the Russian national market for pharmaceutical products grouped by ATC and retail pharmacy sales, it was found that the population has a lack of drugs for digestive tract, respiratory, cardiovascular, urogenital and musculoskeletal systems, as well as dermatological drugs, while the share of dietary supplements production is very large, which indicates the disorientation of Russian companies to the production of necessary medicines. In this regard, it is necessary to improve the policy of stimulating the national production of medicines.

\section{References}

1. Federal State Statistics Service [Electronic resource]. URL: http://www.gks.ru/wps/wcm/connect/rosstat_main/rosstat/ru/ statistics/population/demography/\#

2. The pharmaceutical market of the Russian Federation 2008-2017 DSM report [Electronic resource]. URL: http://dsm.ru/docs/analytics/farmrinok_roccii. _itogi_2017.pdf

3. The population of the world [Electronic resource]. URL: http://naseleniye. population.city/world/ 
4. Earth population counter [Electronic resource]. URL: https://countrymeters.info/ru/World

5. Information and analytical portal of the GC "Remedium" [Electronic resource]. URL: http://remedium.ru/news/detail.php?ID=74439 \&view_result=Y

6. The official website of the World Health Organization. Oncology statistics [Electronic resource]. URL: http://www.who. int/ru/news-room/fact-sheets/detail/cancer

7. The official website of the Federal Service for Supervision of Consumer Rights Protection and Human Well-Being. Infectious morbidity in the Russian Federation [Electronic resource]. URL: http://rospotrebnadzor.ru/activities/statisticalmaterials/statictic_details.php?ELEMENT_ID=9284

8. Report of the World Health Organization on the global fight against tuberculosis [Electronic resource]. URL: https://www.who. int/tb/publications/global_report/gtbr2017_executive_summary_ru.pdf?ua=1

9. L.V. Shabalina, N.Yu. Masliy, Development trends of the world pharmaceutical market. Mat. of the 1st Repub. Scie. and Pract. Conf. "Modern World Economy: Challenges and Reality", Donetsk, November 21, Donetsk: DonNTU, pp. $102-108$ (2018)

10. The official website of the World Health Organization. National Essential Medicines Lists [Electronic Resource]. URL: http://apps.who.int/medicinedocs/documents/s19766en/s19766ru. pdf? ua = 1

11. L.V. Shabalina, N.Yu. Masliy, Prospects for the development of the Russian pharmaceutical industry in the world market. Proc. of the XIVth Intern. Scie. and Pract. Conf, "Ec. and Market. in the XXI Century: Prob., Exper., Prosp.", Donetsk: DonNTU, pp. $601-607$ (2017)

12. What should the Baltic be protected from today? [Electronic resource]. URL: http://www.nkj.ru/news/21917/ 